$\begin{array}{ll} & \text { Etnográfica } \\ \text { etnográfica } & \text { Revista do Centro em Rede de Investigação em }\end{array}$

Antropologia

vol. 23 (1) | 2019

Vol. 23 (1)

\title{
Usos y creencias asociados a los almanaques Mac Donald y Bristol en las islas de Providencia y Santa Catalina, Colombia
}

Uses and beliefs related to Mac Donald and Bristol almanacs in Old Providence and Santa Catalina islands, Colombia

\section{Sandra Correa-Aristizábal y Sandra Turbay}

\section{(2) OpenEdition}

\section{Journals}

Edición electrónica

URL: https://journals.openedition.org/etnografica/6285

DOI: 10.4000/etnografica.6285

ISSN: 2182-2891

\section{Editor}

Centro em Rede de Investigação em Antropologia

Edición impresa

Fecha de publicación: 1 febrero 2019

Paginación: 49-68

ISSN: 0873-6561

\section{Referencia electrónica}

Sandra Correa-Aristizábal y Sandra Turbay, «Usos y creencias asociados a los almanaques Mac Donald y Bristol en las islas de Providencia y Santa Catalina, Colombia», Etnográfica [En línea], vol. 23 (1) | 2019, Publicado el 21 marzo 2019, consultado el 19 enero 2022. URL: http:// journals.openedition.org/etnografica/6285 ; DOI: https://doi.org/10.4000/etnografica.6285

\section{(c) (†) 8}

Etnográfica is licensed under a Creative Commons Attribution-NonCommercial 4.0 International License. 


\section{Usos y creencias asociados}

a los almanaques Mac Donald

\section{y Bristol en las islas de Providencia y Santa Catalina, Colombia}

\section{Sandra Correa-Aristizábaly Sandra Turbay}

En este artículo se caracterizan los usos que hacen los raizales de las islas de Providencia y Santa Catalina de los almanaques Bristol y Mac Donald. La investigación etnográfica permite mostrar cómo en estos folletos se desdibujan las fronteras entre el conocimiento científico y el conocimiento local y cómo ellos articulan dimensiones naturales y culturales del mundo vivido. Las creencias asociadas a estos calendarios y el empleo de los mismos en la vida cotidiana revelan aspectos políticos e históricos conflictivos de las relaciones de los isleños con la Colombia continental. Dichos vínculos entre usos y creencias han sido obviados en las abundantes etnografías hechas en la zona.

PALABRAS-CLAVE: almanaques, calendarios, conocimiento local, etnoclimatología.

Uses and beliefs related to Mac Donald and Bristol almanacs in Old Providence and Santa Catalina islands, Colombia - This article characterizes the uses of Bristol and Mac Donald almanacs between Raizal people of Providencia and Santa Catalina islands. Ethnographic research in these Caribbean islands shows how these publications blur the borders between scientific and local knowledge and how they articulate natural and cultural dimensions of the lived world. The beliefs associated with these calendars and their use in everyday life reveal political and historical conflictive aspects of the islanders' relations with mainland Colombia. These links between uses and beliefs have been overlooked in the many ethnographies made in the area.

KEYWORDS: almanacs, calendars, local knowledge, ethnoclimatology.

CORREA-ARISTIZÁBAL, Sandra (sandra.correar@upb.edu.co) - Centro de Formación Humanista, Escuela de Ciencias Sociales y Humanas, Universidad Pontificia Bolivariana (UPB), Montería, Colombia.

TURBAY, Sandra (sandra.turbay@udea.edu.co) - Departamento de Antropología, Universidad de Antioquia (UdeA), Colombia. 


\section{INTRODUCCIÓN}

El cambio climático genera una seria amenaza para las poblaciones isleñas que no se equipara al escaso poder político que estas tienen en los escenarios internacionales donde se acuerdan las medidas de mitigación (Barnett 2001). ${ }^{1}$ Los estados isleños han insistido en la necesidad de reducir la emisión de $\mathrm{CO}_{2}$ a niveles que impidan un aumento de la temperatura del planeta por encima de $1,5^{\circ} \mathrm{C}$ durante el siglo XXI (Weir, Dovey y Orcherton 2017). El Acuerdo de París se hizo alrededor de la meta de $2^{\circ} \mathrm{C}$ y el consenso ya se empieza a desmoronar con el anuncio del retiro de los Estados Unidos hecho por el presidente Trump en mayo de 2017 (Aldaz Berruezo y Díaz Jiménez 2017). En el ámbito local, las poblaciones isleñas tienen el reto de generar capacidades de adaptación que les permitan reducir su vulnerabilidad frente al cambio climático y frente a la exacerbación de los eventos climáticos extremos que conlleva.

Dentro de las capacidades de adaptación prioritarias está la apropiación social de los conocimientos científicos sobre el clima y el tiempo atmosférico por parte de las comunidades, lo cual va más allá de la difusión de información, pues se pretende que la gente use los resultados de la ciencia para tomar decisiones cotidianas. La reducción de la vulnerabilidad pasa por el diseño de estrategias variadas, ágiles, amigables y efectivas de divulgación de la información meteorológica. En ese sentido, nos parece importante comprender las razones de la eficiencia comunicativa de los almanaques Mac Donald y Bristol en Providencia y Santa Catalina.

Los almanaques hacen parte de nuestra vida cotidiana, están en los hogares y en las oficinas, nos ayudan a organizar nuestra agenda pues siempre incorporan el calendario del año como elemento central, pero también tienen otros usos. Dura (2005) indica que su origen se remonta al siglo XVI y que su difusión se amplificó con la invención de la imprenta y el descubrimiento de América. Esta autora asocia los almanaques a una cultura popular del impreso que incluía gacetas, textos de devoción, imágenes, panfletos y volantes, que tuvieron una amplia circulación en Europa entre los siglos XVIII y XIX. Sin embargo, destaca algunas características distintivas de los almanaques como el tener una matriz textual que incluía el calendario, el horóscopo y las fiestas religiosas, a los cuales se les fueron agregando temáticas que podrían variar de un calendario a otro: las fases de la Luna, observaciones astronómicas, previsiones climáticas útiles para los campesinos, pronósticos de catástrofes

1 Este texto fue escrito gracias a una beca de Colciencias para doctorados nacionales (convocatoria 494 de 2009) otorgada a la primera autora de este artículo. La tesis de la cual se deriva el escrito (Correa Aristizábal 2013) fue desarrollada en el grupo de investigación Medio Ambiente y Sociedad (Maso) de la Universidad de Antioquia. Además, las autoras agradecen a los evaluadores del artículo y a la comisión editorial de la revista por sus comentarios y sugerencias. 
colectivas, preceptos morales, biografías, poemas, medicina doméstica, etc. Los almanaques tienen, según esta investigadora, un contenido ameno, ligero y variado, un lenguaje simple y una impresión de poca calidad que abarata su costo; todas esas cualidades contribuyeron a reforzar su dimensión pedagógica y los convirtieron en un instrumento para la educación del pueblo alfabeto o semi-analfabeto. De esta manera, los almanaques habrían estado ligados a un proyecto de civilización y progreso, a la divulgación de valores morales y códigos de conducta, e incluso a la difusión de virtudes republicanas, como ocurrió durante la Revolución Francesa.

Los almanaques eran, después de la Biblia, la publicación más común en los hogares ingleses del siglo XVII y, según Hetherington (1975), durante ese siglo se publicaron alrededor de dos mil ediciones diferentes que podrían haber llegado a tres o cuatro millones de copias, dirigidas al "hombre de la calle" que apenas sabía leer. El éxito de los almanaques no reside en la actualidad de los conocimientos científicos que difunde y tampoco en el nivel de confiabilidad de sus pronósticos. Hetherington (1975) muestra que en el siglo XVII los almanaques eran hechos por personas sin una sólida formación académica y que cuando dedicaban un espacio a la astronomía, se limitaban a retomar los planteamientos de la época de Copérnico.

En América, el primer almanaque fue publicado en 1689 y a principios del siglo XIX ya muchos pueblos tenían uno o dos. Las ciudades más grandes tenían hasta una docena, su carácter era regional y estaban dirigidos a una audiencia popular conformada por trabajadores, granjeros, pescadores, marineros, etc. (Dodge 1985). Los almanaques no eran solamente objeto de lectura, en los archivos históricos se conservan algunos que fueron utilizados por sus dueños para escribir sus diarios, hacer listas personales, anotar oraciones o desarrollar su expresión creativa (Eamon 2012). Llaman la atención los almanaques de Nathaniel Ames y Benjamín Franklin, quienes difundieron las ideas de Newton entre los colonos norteamericanos ávidos de material de lectura; en estos exaltaban el poder de la razón que lograba descubrir leyes de la naturaleza que expresaban la bondad y la sabiduría divina (Jorgenson 1935).

Kerr (1982) muestra cómo algunos científicos contrastaron los pronósticos que hizo el Old Farmer's Almanac entre 1975 y 1980 con el tiempo atmosférico real y encontraron una muy baja correlación. Si bien hoy en día los avances de la ciencia hacen más confiables los pronósticos meteorológicos, es imposible atribuir la popularidad de estos escritos a la precisión de sus predicciones, pues su área de influencia es muy vasta y en ella el tiempo atmosférico presenta una gran variabilidad. Más bien, habría que explorar cómo dichos folletos se incorporan en los patrones simbólicos, en la organización social y en los procesos identitarios de las poblaciones que los utilizan.

Puesto que la función de los almanaques va más allá de la consulta del calendario, su vigencia está garantizada, independientemente de la generalización 
de agendas o calendarios impresos o electrónicos. Además de su indudable valor estético, que en ocasiones los convierten en objeto de decoración en los hogares, también se vuelven fuente de consulta para la toma de decisiones, especialmente en las zonas rurales donde los agricultores acompasan sus actividades con el ritmo de las estaciones o de los cambios en el clima o en las fases de la Luna.

Los almanaques suelen retomar ideas presocráticas sobre la composición de la materia, las cuales suscitaron las reflexiones de Platón sobre la composición del universo basada en cuatro elementos (Glacken 1996; Cañas Quirós 2012) y tuvieron correspondencia con la doctrina de los humores de Hipócrates de Cos (460-377 a.C.). ${ }^{2}$ De estas se desprendieron teorías sobre la influencia del clima en la salud humana, animal y vegetal. ${ }^{3}$ Por eso, aún es común encontrar en algunos almanaques recomendaciones para la vida diaria que retoman ese tipo de teorías que, por lo demás, tuvieron profundo arraigo popular en Europa.

El Almanaque Pintoresco de Bristol fue publicado por primera vez en 1843 en Nueva Jersey, Estados Unidos, por el químico y farmaceuta Cyrenius Chapin Bristol, inventor del famoso jarabe de zarzaparrilla. ${ }^{4}$ Bristol distribuía el almanaque, que era más un manual para los usuarios de sus productos, en distintas boticas de la costa este de Estados Unidos, y, para hacerlo más ameno, le fue introduciendo el santoral, los cuentos y los chistes (Castiblanco Roldán 2010). La empresa de Bristol fue adquirida por D. T. Lanman, quien también había comprado la empresa productora del Agua de Florida, fundada en 1808 por John Murray. ${ }^{5}$ La nueva compañía empezó a exportar sus productos y el almanaque hacia Centroamérica y, a finales del siglo, hacia Suramérica. Desde entonces se han publicado ediciones especializadas para cada país.

De su lado, el Almanaque Mac Donald (Mac Donald's Farmers Almanac) fue creado en Nueva York en 1897, por el médico Jeremiah Mac Donald, quien lo

2 Glacken (1996) ubica el origen de la doctrina de los cuatro elementos en las especulaciones de los filósofos jonios sobre la composición básica de la materia. Algunos autores, como el mismo Glacken (1996) y Cañas Quirós (2012), les confieren continuidad histórica a estas ideas, con modificaciones generadas por el tiempo y por otros pensadores, y las relacionan con la doctrina hipocrática de los humores. Académicos como López Piñero y Frequet Febrer (1995) o López-Austin (1995) sostienen que parte de estas ideas, al menos en cuanto a la oposición de cualidades frío-calor, son elementos constitutivos de algunas cosmovisiones indígenas desde tiempos prehispánicos.

3 Las teorías sobre el efecto del frío, del calor, de la sequía, de la humedad y de los vientos sobre el cuerpo humano fueron derivando en el determinismo ambiental que correlacionaba el clima con el aspecto físico y el carácter nacional (Glacken 1996).

4 Información en "Cyrenius C. Bristol papers: collection overview", University of Rochester | River Campus Libraries, disponible en $<$ http://rbscp.lib.rochester.edu/806 > (última consulta en diciembre de 2018).

5 Información en < http://www.lanman-and-kemp.com/history.htm > (última consulta en diciembre de 2018). 
utilizaba para promover sus medicamentos, la mayor parte de ellos con propiedades tónicas y purgantes. Como en 1904 se prohibió en Estados Unidos la consulta médica y el despacho de medicamentos por correo, la empresa conservó únicamente el almanaque, que ha permanecido como un negocio familiar por cuatro generaciones, orientado a dar consejos a una clientela rural interesada especialmente por nuevos desarrollos de la agricultura y la ecología. ${ }^{6}$

Estos almanaques son ampliamente acogidos por varias razones. Además de ser asequibles a personas que tienen un nivel básico de lectura, están ilustrados, son entretenidos, estimulan la curiosidad, dan consejos útiles, pueden ser consultados durante todo el año, su costo es mínimo y, sobre todo, combinan el conocimiento científico sobre el clima y el tiempo atmosférico con creencias mágicas y religiosas. En ellos confluyen calendarios anuales, lunares y diarios exhibiendo concepciones del tiempo basadas en diferentes temporalidades. Cada año cambian su contenido, el cual siempre está asociado a los períodos de 29 días de los ciclos lunares, y además tienen indicaciones diarias en relación con las mareas. También poseen conexiones con indicadores y predictores calendáricos, ofrecen información del santoral católico y del horóscopo, y articulan la astrología, las ciencias ocultas, la medicina popular y las observaciones sobre la naturaleza. Melo (2011) afirma que estos son escritos sobre la medición y paso del tiempo, ya que plantean la posibilidad de la previsión, y menciona su relación con la tradición profética de Brasil del siglo XIX, ligada a las sequías, inundaciones y epidemias. Tal como ocurre en la actualidad con los profetas de la lluvia en el nordeste brasilero (Taddei 2009), los almanaques disminuyen la ansiedad, aminoran la sensación de imprevisibilidad y crean una imagen de futuro compartida.

Drew (2005) plantea que la valoración del conocimiento local permite mitigar las desigualdades frente al discurso científico y promueve una visión holística del entorno en tanto muchos grupos humanos no poseen divisiones tajantes entre naturaleza y cultura. En la filosofía moral de Occidente, en la época clásica, los humanos se concebían como separados y superiores a los animales (Howell 2001), pero fue en el Renacimiento cuando la distinción entre naturaleza y cultura se adoptó y se fortaleció en Europa (Pálsson 2001; Ulloa 2001): el ambiente, el conocimiento y el aprendizaje fueron construidos de manera diferente y la naturaleza se convirtió en algo que era necesario traducir (Pálsson 2001). Wallerstein (1996) explica que la llamada "visión clásica de la ciencia” tenía como premisa la división entre naturaleza y ser humano, cuerpo y mente, mundo físico y espiritual. Estas ideas se fueron implantando en las ciencias y disciplinas nacientes a finales del siglo XIX.

6 Información en “The history behind Dr. MacDonald's Farmer Almanac”, en < http://www.macdo naldsfarmersalmanac.com/history.html > (última consulta en diciembre de 2018). 
A partir de tales distinciones, el conocimiento local y el científico fueron vistos como dos ámbitos opuestos. El primero se asoció a lo natural, a los grupos humanos de los países no industrializados y a los campesinos, mientras que el segundo se relacionó con sociedades occidentales. No obstante, en las últimas décadas algunos trabajos han resaltado las bases del conocimiento científico y las formas en las cuales los saberes asociados con la ciencia se imbrican en las prácticas locales. Por ejemplo, Golinski (2003) señala que la conformación histórica de la meteorología tiene raíces en el conocimiento local, en los diarios de físicos y filósofos naturales. Asimismo, Strauss (2009), a partir de sus estudios con habitantes de una villa en Suiza, relaciona el conocimiento local con aspectos del desarrollo histórico del conocimiento científico sobre el tiempo atmosférico y las normas para la predicción del clima. La autora expone que no hay una progresión simple entre lo tradicional y lo moderno, ni entre lo local y lo global, sino que se presentan relaciones no lineales en las que los dos aspectos se combinan. También argumenta que el conocimiento científico descansa, en ocasiones, en la documentación subjetiva de individuos, cuya visión es personal; por lo tanto, existen puentes entre la experiencia, la tradición y las formas de predicción climática. Otros autores exponen que el conocimiento científico es una de las muchas fuentes de los saberes locales (Rudiak-Gould 2013), los cuales requieren de bases múltiples para funcionar ante la alta incertidumbre que plantean los cambios en el tiempo atmosférico (Roncoli et al. 2003; Orlove et al. 2010) y, en general, en las vidas diarias de las personas.

Siguiendo los planteamientos de Lejano, Tavares-Reager y Berkes (2013), el conocimiento local es tomado como el complejo conformado por la interacción entre conocimientos y creencias; los autores retoman a Tim Ingold para complementar la díada con un tercer elemento: la práctica, que es la esencia de este tipo de saberes, pues por medio de ella son aprendidos y transmitidos. El conocimiento local es considerado dinámico ya que posee incorporaciones, pérdidas y modificaciones, está conformado por saberes transmitidos de generación en generación y desarrollados en un sitio particular, pero también por conocimientos de orígenes múltiples que son aplicados en la localidad, bajo marcos selectivos de carácter cultural (Correa Aristizábal 2013). Es decir, es adaptativo, cambiante y, al mismo tiempo, retiene una continuidad cultural (Lejano, Tavares-Reager y Berkes 2013). Tal y como señala Taddei (2015), al hablar de localidad en relación con los saberes se hace referencia a una discusión de escalas de acción en el contexto de la existencia social y cultural.

\section{ÁREA DE ESTUDIO}

El Archipiélago de San Andrés, Providencia y Santa Catalina está ubicado en el Caribe occidental, entre los paralelos $10^{\circ}$ y $18^{\circ}$ de latitud norte y los meridianos 
$78^{\circ}$ y $82^{\circ}$ de longitud oeste (GDASAPSC 2012). Limita con Panamá, Costa Rica, Nicaragua, Honduras, Jamaica, Haití y República Dominicana. Está localizado a $750 \mathrm{~km}$ al noroeste de la costa Caribe de Colombia, a $270 \mathrm{~km}$ de Colón en Panamá y a 125 km de Bluefields en Nicaragua (Aguilera Díaz 2010; GDASAPSC 2012). Cuenta con $53 \mathrm{~km}^{2}$ de tierras emergidas, de las cuales $45 \mathrm{~km}^{2}$ corresponden a las islas habitadas de San Andrés, Providencia y Santa Catalina; los $8 \mathrm{~km}^{2}$ restantes pertenecen a algunos cayos e islotes. Las islas de Providencia y Santa Catalina están ubicadas a $90 \mathrm{~km}$ al norte de San Andrés, entre los $12^{\circ}$ y $16^{\circ}$ de latitud norte y los $78^{\circ}$ y $82^{\circ}$ de longitud oeste (Velásquez Calderón y Santos-Martínez 2010). Poseen $18 \mathrm{~km}^{2}$ de área terrestre y cuentan con 4118 habitantes (Márquez Pérez 2013).

Las principales actividades económicas de la zona son el turismo no masivo (de buceo, de sol y playa); la pesca, que durante las últimas décadas ha pasado del autoabastecimiento a cubrir las necesidades de los hoteles de estas islas y de San Andrés; la agricultura de panllevar, que tiene peso en la economía familiar de los raizales; y en menor proporción están la producción de carne de cangrejo negro, los empleos brindados por la administración municipal y el comercio. La poliactividad que caracteriza esta sociedad permite en gran medida hacer frente a la variabilidad climática y a otros elementos relacionados con las características del mercado laboral de la zona, dando cierta autonomía e independencia para elegir las ocupaciones u oficios a realizar. Por este motivo, cuando se habla de pescadores, agricultores, personas dedicadas al turismo o empleados oficiales, se hace referencia a grupos heterogéneos. En estas comunidades se pueden hallar pescadores que hacen sus capturas desde la playa o cerca de esta en pequeñas embarcaciones, mientras que otros viajan varias millas hasta los Cayos del Norte. ${ }^{7}$ Algunos combinan pesca con agricultura y turismo, y van organizando el tiempo que le dedican a cada una de las actividades de acuerdo con las circunstancias cotidianas, las oportunidades, las necesidades, la productividad y el disfrute.

La población local es el resultado de una mezcla con fuertes componentes ingleses y afrocaribeños, lo cual está representado en su idioma, que es una combinación de inglés con dialectos africanos e incorporaciones posteriores del español (Correa Aristizábal 2013). Sus construcciones identitarias resaltan la herencia de Gran Bretaña, y en especial la de los piratas y bucaneros ingleses que desafiaron el poderío español (Wilson 2004). Aunque todavía sobreviven las redes caribeñas que los unen con los bordes costeros de la región y con las Antillas, y estas se mantienen en las memorias de los adultos y mayores, son cada vez menos claras para las nuevas generaciones (Correa Aristizábal 2013). El endurecimiento de los límites, los diferendos fronterizos

$7 \quad$ Las capturas desde la playa se dan principalmente entre mujeres y niños, pero algunos hombres lo hacen como una actividad lúdica que genera unas pocas capturas. 
y la disminución de los intercambios comerciales directos, que eran tradicionales entre estas zonas, han llevado a su debilitamiento (Correa Aristizábal 2013).

Estos imaginarios sobre su identidad están relacionados con la resistencia a los procesos de colombianización, nombre que se le ha dado a un conjunto de estrategias del Estado dirigidas a asimilar a los sanandresanos a la cultura dominante de Colombia, a partir de parámetros considerados como representativos de esta (Charry Joya 2002). Dichos procesos se han dado en diferentes momentos de la historia del país y han incluido la imposición del español y del catolicismo a un pueblo hablante de inglés criollo y de base protestante. Se hace evidente en aspectos paisajísticos y en las formas de asentamiento, principalmente en San Andrés, y en procesos de expropiación territorial, exclusión y sobrepoblación (Guevara 2007). La colombianización contemporánea ha tomado la forma de embates constantes para la implementación de proyectos que buscan minar el control local sobre los recursos y sectores importantes para la economía local, en especial en el campo del turismo. Estos procesos, tanto pasados como presentes, han conllevado una serie de cambios y fracturas en detrimento de los raizales (Robinson Saavedra 2005) y aún tienen consecuencias en campos como el educativo, en donde las clases se dictan en español cuando el idioma local es el inglés creole. Todo esto sucede a pesar del reconocimiento que hace la Constitución de 1991 de los raizales como uno de los grupos étnicos del país que debe ser protegido.

\section{METODOLOGÍA}

Este artículo se deriva de la tesis presentada por la primera autora del artículo para optar al título de doctora en Ciencias Sociales (Correa Aristizábal 2013). El estudio se desarrolló entre septiembre de 2010 y agosto de 2015.

La elección del lugar estuvo asociada a la idea de la etnografía como un espacio para mirar lo ordinario, o naturalizado en el caso del clima, en lugares donde toma formas no acostumbradas, con el fin de mostrar cómo su significado varía de acuerdo con los grupos humanos y sus patrones de vida (Geertz 2003). El pre campo tuvo lugar del 24 de marzo al 4 de abril de 2010, mientras que el trabajo de campo se desarrolló entre septiembre de 2010 y enero de 2012. La tesis fue sustentada en agosto de 2015.

La pesquisa, de tipo cualitativo, se basó en la etnografía como enfoque, método y texto (Guber 2011). ${ }^{8}$ Se recopilaron 44 entrevistas de miembros

8 La etnografía, como enfoque, guía el conocimiento y la práctica para entender los universos de sentido y las lógicas de acción social del investigador y de sus interlocutores (Guerrero Arias 2002; Guber 2011 ). Como método, aporta procedimientos de corte disciplinar que se ponen en práctica de manera sistemática, pero también abierta y flexible, en una aproximación en la que se concatenan situaciones de interacción social, en un contexto definido y con componentes normativos generales, [continua] 
de las comunidades isleñas. Los entrevistados fueron informados del tema de la pesquisa y de su participación en esta. Las sesiones grabadas fueron registradas con consentimiento informado previo. Se procuró entrevistar adultos, es decir personas mayores de 25 años, y se tuvo preferencia por mayores de 60 años. ${ }^{9}$ Sin embargo, esto no fue excluyente, ya que se hallaron menores de 25 años con saberes relacionados con el tema. Los datos recolectados en campo se incluyeron en el software Atlas ti, que se usó en un nivel textual, para codificar y rastrear datos de manera rápida y organizada. Esto permitió desagregar y clasificar de acuerdo con las categorías analíticas.

\section{RESULTADOS}

La presencia o ausencia de lluvias es la característica principal a partir de la cual los raizales definen las estaciones, sus nombres, ubicación en el año y sus cambios. En la ideación local del calendario climático anual, es decir la manera en la cual los isleños perciben la sucesión estacional a lo largo del año, la época seca o verano va desde enero hasta mediados de mayo; y la temporada de lluvias o invierno se da desde mediados de mayo hasta diciembre o enero. Esta población insular tiene sistemas de observación detallados de los cambios estacionales, en especial frente al recurso hídrico, pues es decisivo para la vida en las islas dado que las corrientes de agua son estacionales y dependen del agua de la lluvia para el consumo humano. Sus formas de lectura y predicción les ha permitido desarrollar una descripción local de las estaciones coincidente con los datos científicos, en especial con los patrones de pluviosidad media mensual de la zona.

Las vidas de los isleños están acompasadas con las estaciones climáticas y con el tiempo atmosférico. En este sentido, la poliactividad es un mecanismo que coincide con la estacionalidad de las actividades realizadas en las islas: la agricultura, la pesca y el turismo no proveen ingresos de manera constante. Las dos primeras actividades son afectadas de manera directa por condiciones climáticas adversas y por calendarios de siembras y capturas. Es decir que tienen momentos de alta y baja productividad, y en ocasiones se suspenden. De igual manera, el turismo tiene temporadas de afluencia variable y también se ve afectado por condiciones climáticas. La poliactividad está fuertemente arraigada en la plasticidad de la población para la organización de las actividades diarias e incluso se relaciona con creencias religiosas que dan cuenta de unas lógicas que consideran la existencia de un orden y de unos ciclos

para conocer las perspectivas y visiones de las comunidades (Mora Nawrath 2010). La etnografía como texto es la construcción de la realidad social condicionada por la escritura (Pineda Camacho 1987).

9 Se tuvo preferencia por los adultos mayores en tanto han experimentado un contacto prolongado con el territorio, los ciclos climáticos y de vida en las islas, así como con los almanaques. 
divinos. Por ejemplo, los isleños adultos ven el clima como un elemento que puede explicarse científicamente y también reconocen y comprenden el ciclo del agua, sin embargo estos aspectos son tomados como parte de los ciclos naturales creados por Dios. Por este motivo, si la lluvia entorpece las labores al aire libre se constituye un llamado a suspenderlas o a cambiarlas por otras. Esta es determinante para seleccionar las actividades a desarrollar y su presencia generalmente implica cambio de planes. Muchos jóvenes muestran posturas menos asociadas a la voluntad divina, pero son reacios a hacer planes a largo plazo, pues lo consideran una pérdida de tiempo por la incertidumbre del día a día. Por tanto, gran parte de sus decisiones laborales y productivas son tomadas en lapsos cortos.

Los isleños usan varias fuentes de pronóstico del tiempo atmosférico a corto plazo que les permiten programar sus vidas; sintonizar radio o ver televisión son dos formas populares y sencillas a las que todos tienen acceso, pues comúnmente los hogares cuentan con los aparatos para hacerlo, y estos medios son usados por personas de todas las edades. ${ }^{10}$ Para profundizar o hacer seguimiento de los pronósticos en la web, los más jóvenes usan teléfonos inteligentes, tabletas y computadoras. La información hallada es comentada y discutida con familiares y amigos, en especial con los mayores ya que muchos no manejan este tipo de tecnología. Los adultos y mayores llaman o van a las oficinas locales, principalmente a Capitanía de Puerto y a la Cooperativa de Pescadores, pues son lugares en los cuales los pronósticos están a la orden del día. En alta mar, los pescadores y navegantes tienen comunicación constante por radio y, si están cerca de las islas y hay señal, usan los celulares. Esta amplia gama de opciones es complementada por las observaciones locales, en las cuales se toman en consideración indicadores (biológicos, físicos-geográficos y meteorológicos) y predictores (meteorológicos, biológicos, físicos, sensoriales, astronómicos y calendáricos).

En este marco los calendarios son la faceta escrita y permanente para los pronósticos. Se conservan y usan día a día durante el año. Si bien estos escritos son la única fuente de diagnóstico anual para los isleños, pues incorporan el calendario gregoriano, no son usados a largo plazo. Los raizales los utilizan con frecuencia para programar sus actividades en lapsos que van desde horas hasta

10 En Colombia no existen los canales de pronóstico del tiempo. El tiempo atmosférico se cubre a partir de noticias relacionadas con eventos extremos junto a las cuales se mencionan los pronósticos de entidades como el Instituto de Hidrología, Meteorología y Estudios Ambientales, instancia estatal que pertenece al Sistema Nacional Ambiental. De acuerdo con Lema Veléz et al. (2017), en el país la televisión es el medio más popular a través del cual las personas reportan la obtención de información científica; según los autores, en este discuten temas como los eventos de El Niño o La Niña a partir de términos inadecuados, pues las fuentes y los testimonios no se originan en investigadores o expertos del clima. Sin embargo, la información relevante para los raizales está centrada en los pronósticos que sí tienen como fuente la agencia estatal y que acompañan los reportes de desastres o eventos extremos. 
un poco más de 30 días. Esto muestra una coincidencia entre las costumbres locales y las posibilidades que brinda el almanaque en cuanto a medición del tiempo mes a mes, de las fases de la Luna y de fenómenos que cambian en cuestión de horas, como las mareas.

Entre los isleños, además del tiempo atmosférico, el calendario lunar es considerado para la programación y el desarrollo de prácticas económicas, lúdicas y sociales. Por ejemplo, el almanaque Mac Donald ofrece listados de fechas adecuadas para plantar durante el año y explica que hay conexiones entre los cambios de la Luna y la temperatura de la tierra: "About the time of the Moon's last quarter, the interior of the Earth cools [...] Crops whose growth is above the Earth should be planted when the Earth is internally warm" (anónimo 201 l: s.p.). Este elemento también tiene vínculos con las concepciones sobre la influencia del calor y del frío en los procesos de salud y enfermedad presentes en el núcleo de creencias locales, que aplican tanto para las plantas como para los animales y humanos.

En relación con los orígenes de la díada frío/calor como parte del pensamiento occidental, Glacken (1996) expone que las preguntas de los griegos por las relaciones entre los seres humanos y la tierra englobaban tanto teorías abstractas sobre los orígenes del mundo como reflexiones sobre técnicas prácticas de agricultura. Cañas Quirós (2012) explica que la transmisión en Occidente de la teoría de los cuatro elementos se dio por medio de la obra de Aristóteles. Estas reflexiones fueron la base para interpretaciones medievales de la naturaleza y dominaron el pensamiento en química, pedología, en la agricultura práctica y en la teoría física del siglo XVIII (Glacken 1996). De manera implícita, en la doctrina de los elementos, se hallaba la idea de los opuestos como caliente/frío o húmedo/seco; esta se hizo extensiva en tanto se consideraba que el cuerpo humano estaba compuesto por los mismos elementos presentes en el mundo (Glacken 1996). Se llegó a sostener que la salud era una mezcla armoniosa, un balance equitativo que podía ser perturbado por la dominancia o exceso de alguno de estos poderes o elementos (Glacken 1996). En la teoría hipocrática de los humores se consideraba que la salud era la apropiada proporción de humores y, por tanto, la dominancia de uno de estos podía ser causada por un elemento externo del ambiente físico, como la temperatura, lo cual podía generar desbalance y enfermedad.

En la agricultura, y su relación con la Luna, los folletos son usados para obtener frutos más grandes, para que las cosechas sean más productivas o para que las podas y la eliminación de malezas sean efectivas. ${ }^{11}$ En la ganadería son consultados para conocer las fechas óptimas para las castraciones y, de acuerdo con un agricultor y ganadero de las islas, para conocer el sexo de los terneros

11 Glacken (1996) señala que en algunas culturas las fases de la Luna ayudaron a medir el paso del tiempo antes de la generalización del año solar. 
[E12,2010]. Este adulto mayor anotó que él consulta la fase de la Luna y, si las vacas deben parir cerca del cambio, puede saber con anticipación si es macho o hembra, pues en su opinión los primeros nacen cerca de Luna llena y las segundas, de Luna nueva. En este punto se muestra la Luna como un elemento que ayuda a ordenar la vida y el tiempo entre algunas personas de zonas rurales, como lo señala Carreño: "El influjo lunar en los procesos agrícolas es tema muy repetido en estos libros [sic] [...] Lo encontramos en el Lunario de Jerónimo Cortés, cuyo nombre es claro exponente de tales creencias" (1991: 213). ${ }^{12}$

Los almanaques también representan una frontera difusa entre lo escrito y lo oral, pues en este tipo de folletos se dieron las primeras expresiones de la palabra escrita (Melo 2011; França Júnior 2007). En la actualidad son altamente difundidos en comunidades con bajos niveles de lectura (Botrel 2006), como lo son Providencia y Santa Catalina, lugares en donde hay una mayor inclinación hacia la oralidad y, en el caso de los medios de comunicación, hacia los audiovisuales. No obstante, el lenguaje sencillo y ameno que caracteriza estos folletos, así como los múltiples temas que abordan, los hace altamente populares entre las comunidades locales.

Los almanaques funcionan como textos en los que se diluyen los saberes científicos en relación con los saberes populares (França Júnior 2007). RudiakGould (2011) explica que los discursos científicos, en especial aquellos asociados al clima - o en este caso a las mareas -, no están confinados a círculos de especialistas, élites educadas o sociedades occidentales, sino que se hallan imbricados en los sistemas de conocimiento de las comunidades. Este autor afirma que el conocimiento científico agrega información relevante, que es previamente evaluada a partir de las observaciones locales. Por ejemplo, en Providencia, un pescador local asoció los datos ofrecidos por los almanaques con el comportamiento de las especies e hizo referencia a la validez de esta información por su cientificidad y su aplicabilidad, demostrando cómo los datos generales sobre las mareas son llevados a la práctica y adaptados a los saberes previos y a las condiciones específicas del lugar:

"Generalmente esos días que ellos [los almanaques] señalan como buenos para la pesca son los que se acercan a los mejores días de alineación y de mareas, y de buenas mareas, de mareas altas. Lo otro, la Luna mueve las mareas, o sea la ciencia está en esto, el movimiento de la Luna genera un movimiento en las mareas de acuerdo a la alineación que tenga la Luna con el Sol. Tenés cuatro alineaciones en veinticuatro horas, tenés la alineación cuando sale la Luna, no importa que sea Luna totalmente oscura, pero tenés en cuenta cuando ella está saliendo. Un tiempito antes de salir la Luna

12 El almanaque Lunario de Jerónimo Cortés circuló en España entre el siglo XVI y principios del siglo XX (Carreño 1991). 
comienza el movimiento de las especies. Cuando ella está en el cenit, o cerca del cenit, comienza otro movimiento de las especies de alimentación, ¿no? [...]. Y cuando ella está por caer, yo lo mido con una cuarta antes de caer. [...] yo generalmente comienzo a buscarlos, o sea, estamos hablando de procesos de seis horas en los que ocurren las alineaciones; entonces generalmente esas alineaciones generan movimientos de marea, no importa que la marea sea extremadamente baja, ella se altera un poquito y sube, no importa que sea extremadamente alta, ella sube un poquito, y esa alteración es lo que genera el movimiento de las especies menores" [E62, 2011].

Los procesos de ensayo y error coadyuvan a la construcción de saberes ligados al territorio emplazando datos genéricos o científicos. Los datos generales, y quizás no tan precisos, que ofrecen los almanaques son contrastados, lo cual, acorde con los planteamientos de Rudiak-Gould (2011), expone la "triangulación” de fuentes de información y el diálogo de doble vía entre datos y prácticas en el contexto del conocimiento local. Se puede afirmar que no se trata de una repetición mecánica de aquello que se lee sino de una orientación a partir de datos y observaciones.

Las discusiónes en torno a los calendarios, las predicciones y los contenidos de los almanaques son comunes en la localidad. Lo anterior se da en encuentros espontáneos que se desarrollan en espacios públicos (al lado de la carretera, bajo un árbol o en las playas) en los cuales priman las historias anecdóticas y los debates sobre vivencias, conceptos y su aplicación local. Lejano, Tavares-Reager y Berkes (2013) plantean que estas narraciones conectan a los seres humanos y a otras partes del ambiente en un todo coherente y muestran cómo los diferentes tipos de conocimiento confluyen en visiones del mundo expresadas en dichas anécdotas orales. Esas narraciones hacen parte de los mecanismos sociales mediante los cuales se adaptan los datos generales a vivencias cotidianas y cercanas a las realidades diarias de los isleños.

Ambos almanaques pueden ser adquiridos con igual facilidad en las islas, ya sea en las casas de algunos adultos mayores que los compran y los revenden, o bien en establecimientos de comercio donde se hallan productos misceláneos. La preferencia por uno $\mathrm{u}$ otro folleto tiene que ver con las percepciones del territorio y, más específicamente, con su pertenencia regional, aspecto hallado entre jóvenes, adultos y mayores; además, tiene vínculos con el pasado, en especial por los choques y las prohibiciones del proceso de colombianización, consideración encontrada únicamente entre los adultos mayores. Es decir que en torno a los escritos en mención se manifiestan fronteras geográficas y culturales.

En cuanto a la percepción del territorio hay dos posturas vinculadas a estos folletos que tienen como base la idea de las islas como una zona de frontera; en ambas el almanaque Bristol, en español y hecho para Colombia, representa el sur, mientras que el Mac Donald, en inglés y diseñado para Estados Unidos, 
representa el norte. Algunos isleños ven su territorio como un lugar que posee características tanto del norte como del sur y por esto combinan los datos de los dos almanaques para aplicarlos en la localidad. Esta combinación de datos la hacen en su día a día, para las predicciones del tiempo y de las mareas, para la salida de la Luna y las fases de esta, entre otros. En contraposición, un grupo de interlocutores no encuentra similitudes entre uno y otro; por este motivo, declaran su preferencia por el texto anglosajón, pues sus pronósticos les parecen más cercanos al territorio insular, tal y como lo expresó un adulto mayor: "Es que el almanaque Mac Donald es más preciso; en cambio el de Colombia, como no somos de allá, de Colombia, estamos diferente [sic]... ${ }^{13}$ Vamos a ser sinceros, pero vamos a hablar la verdad: es más preciso en las horas, los segundos. iTodo es preciso!" [E3 l, 20ll]).

Estas preferencias tienen que ver con el idioma y aspectos históricos que se conservan en las memorias de algunos adultos mayores, como la imposición del español en el archipiélago durante gran parte del siglo XX y los conflictos que esto aún causa en la educación. El mismo interlocutor de la cita anterior explicó:

"Eso [el almanaque] fue traído por los ingleses, como es que las islas tenían más contacto con Gran Caimán... Por ejemplo, hay apellido Whittaker, ese es de Gran Caimán; Bush, también; los Huffington [...] vienen de Gran Caimán porque esos eran ingleses. Es que aquí la gente toda era inglesa [...]. Sí, es que cuando llegaron aquí los curas españoles fue cuando comenzaron a enseñar a las gentes a hablar español [...], Ya exigieron que no enseñaran en inglés porque este es país colombiano, solamente eran los bautistas y los adventistas, esos sí enseñaban su inglés en las escuelas" [E31, 2011].

De esta manera, puede afirmarse que para algunos el Mac Donald tiene un carácter más propio y diferenciado del Bristol, que está hecho para la zona continental del país. Ninguno de los interlocutores manifestó basarse únicamente en el segundo almanaque. Estos elementos dan cuenta de posturas locales frente a temas territoriales, reflejadas en los usos de los folletos y de los datos incluidos en estos, entre los cuales están los de tipo meteorológico. Se le otorga credibilidad a la información en tanto tiene relevancia para la región en la que están ubicadas las islas, de acuerdo con las consideraciones geográficas, culturales e históricas de los raizales. Con base en Taddei (2015), se subraya que los datos y la información que llegan a las localidades se constituyen en meras herramientas, es decir que sólo son recursos usados de manera pragmática en planos de acción más amplios donde hay una participación activa de valores, creencias, imaginarios y construcciones identitarias. 


\section{REFLEXIONES FINALES}

Con base en un análisis de literatura sobre los problemas de la vida social de la información climática, Taddei (2005) señala aspectos que pueden afectar de manera negativa su valor y uso; algunos de estos son: las diferencias existentes entre la comprensión de información abstracta (de carácter científico) y aquella ubicada en las realidades vivenciales de los individuos (asociada a los saberes locales), las dificultades de comprensión de elementos técnicos de los pronósticos por parte de personas no expertas, la asimilación de términos técnicos y los problemas generados por la naturaleza probabilística de la información brindada. De acuerdo con lo expuesto en párrafos anteriores, el conocimiento local tiene una interacción dinámica con los almanaques, pues en ambos hay combinaciones de aspectos tradicionales y modernos, visiones holísticas del mundo y uso de lenguaje sencillo. Los almanaques ponen a disposición datos que pueden ser incorporados en los sistemas existentes a partir de la contrastación de fuentes y de información con aspectos localizados. Adicionalmente, los usos hallados están relacionados con la aceptación de la incertidumbre asociada a los datos, pronósticos o recomendaciones ofrecidas en estos folletos.

Los almanaques y sus usos evidencian la ausencia de progresión simple entre lo tradicional y lo moderno. En ellos se confirman las aseveraciones de Giménez: "Tradición y modernidad solo se oponen como tipos ideales polares. Pero históricamente no son totalmente incompatibles ni excluyentes" (1995: 45). La consulta de estos folletos se conjuga con la información de fuentes como páginas web, medios televisivos y la observación local, pero no los elimina del conjunto de fuentes consultadas a pesar de que su contenido y formato han variado poco desde el siglo XIX (Castiblanco Roldán 2010). Estos textos, cuyo formato fue producido antes de la división cartesiana del conocimiento, muestran cómo la era digital anclada en el saber científico (Melo 2011) no ha reemplazado las formas de pensamiento complejas y holísticas de muchas sociedades contemporáneas. Además, se constituyen en posibilidades para la adaptación de contenidos para comunidades rurales y populares.

En el ámbito geográfico, las islas de Providencia y Santa Catalina pertenecen a un enclave territorial del Caribe colombiano, en sí mismas son un lugar fronterizo en términos limítrofes y culturales. De acuerdo con Meza Ramirez (2006), los territorios fronterizos, que en este caso incluyen tanto al archipiélago como los folletos, se constituyen en ámbitos de transición entre dos o más territorialidades. El carácter fronterizo de los almanaques se expresa en dos elementos: primero, en la combinación entre conocimiento científico y local; segundo, en los discursos asociados a estos, que los muestran como medio de expresión de aspectos simbólicos de carácter político y cultural.

Desde sus inicios estos escritos han mezclado mercadeo de productos para la salud, datos científicos y elementos religiosos y astronómicos. Los almanaques 
son un espacio que amalgama un conocimiento de tipo científico y a la vez popular, que conjuga creencias religiosas con recomendaciones para la vida diaria, tal y como lo hacen los saberes en sí mismos.

En el conocimiento local se consideran múltiples variables para la lectura y predicción del clima y el tiempo atmosférico (Marin y Berkes 2013). No obstante, los grupos humanos combinan en diferentes proporciones las variables que tienen a su disposición para tomar decisiones (Van Kessel y Enríquez Salas 2002; King, Skipper y Tawhai 2008; Ulloa 2011). La poliactividad predominante entre los isleños requiere de información compleja para el desarrollo de sus actividades cotidianas.

Los usos descritos de los almanaques muestran una comprensión de la incertidumbre, ya que la información que brindan no es tomada como una certeza, sino que es triangulada con datos obtenidos de otras fuentes. Es decir que los isleños reconocen que muchos de esos datos no hacen parte de una ciencia "capaz de todo", que actúa en un mundo previsible (Taddei 2005). Por tanto, no hay proyección de grandes expectativas en ellos, sino que los toman como una orientación (Taddei 2005), la cual les permite hacer contrastaciones emplazadas. El hecho de que combinen datos de mareas, tiempo atmosférico o fases de la Luna - elementos que los isleños reconocen como cíclicos, pero no como exactos - con información del santoral católico abre espacios para la expresión de creencias, en especial aquellas vinculadas con la religión y la idea de un orden divino que organiza ciclos naturales y humanos, aspectos que hacen parte del núcleo de la cultura local, en especial entre adultos y mayores.

Ante el llamado que realiza Taddei (2005) de pensar cómo mejorar la efectividad de la comunicación científica en el ámbito del tiempo y del clima, es relevante subrayar las asociaciones que las fuentes de información pueden llegar a tener. En el caso de Providencia y Santa Catalina, los almanaques se enlazan con asuntos de pertenencia cultural y geográfica de su territorio, ubicando los folletos en divisiones norte-sur. En consecuencia, se puede afirmar que, si bien el conocimiento local y los almanaques exhiben visiones holísticas del mundo, no están exentos de dicotomías internas, principalmente en términos de posturas y acciones políticas. Lo anterior refuerza la necesidad de conocer el contexto en el cual los datos son interpretados, pues adquieren una vida propia en el proceso de utilización e incorporación que se da en las localidades, no solo por la apropiación de los datos, sino también por las cargas políticas que estos pueden tomar.

A partir del estudio de los usos y creencias asociadas a los almanaques en esta porción del territorio archipelágico, es posible afirmar que una mejor comprensión de la cultura y del contexto social y político local permite a los investigadores del clima y a los mediadores entre ellos y los usuarios del conocimiento mejorar los procesos de comunicación. Como dice Taddei (2008), la eficiencia de la comunicación meteorológica, y científica, no depende tanto del contexto en el cual la información es emitida sino de la atención que preste- 
mos al contexto en el cual es recibida, y eso puede implicar hacer concesiones terminológicas, identificar intermediarios capaces de hacer traducciones lingüísticas y culturales de la información técnica y hacer investigaciones sistemáticas sobre estrategias comunicativas eficaces en contextos distintos y para poblaciones diversas, dejando de lado las divisiones tajantes entre formas de conocimiento científicas y locales.

Finalmente, se subraya que, tal y como lo señala Melo (201 l), los almanaques han sido ignorados por las ciencias sociales a pesar de que encierran cosmologías, discursos y prácticas ricas en términos culturales. La autora se basa en Gayatri Spivak para resaltar que la condición de subalternidad es la condición del silencio. En el caso de Providencia y Santa Catalina, han sido elementos obviados, o silenciados, por las etnografías que abordan la vida y costumbres de los isleños raizales, a pesar de que son incluidos en campos simbólicos, sociales e identitarios.

\section{BIBLIOGRAFÍA}

AGUilera DíAZ, María, 2010, Geografía Económica del Archipiélago de San Andrés, Providencia y Santa Catalina. Cartagena, Banco de la República/Centro de Estudios Económicos Regionales.

ALDAZ BERRUEZO, Javier, y Julio DÍAZ JIMÉNEZ, 2017, “Situación del convenio marco de Naciones Unidas sobre el cambio climático: resumen de las Cumbres de París, COP2 1, y de Marrakech, COP22", Revista de Salud Ambiental, 17 (1): 34-39.

ANÓNIMO, 201 1, Mac Donald's Farmer Almanac. Binghamton, NY, MacDonald's Almanac Distributors.

BARNETT, Jon, 2001, "Adapting to climate change in Pacific island countries: the problem of uncertainty", World Development, 29 (6): 977-993, DOI: 10.1016/S0305-750X(01)00 022-5.

BOTREL, Jean-François, 2006, "Para una bibliografía de los almanaques y calendarios", Elucidario, I (1): 35-46, disponible en < http://botrel-jean-francois.com/Libro_livre/Bibli._ almana.html > (última consulta en diciembre de 2018).

CAÑAS QUIRÓS, Roberto, 2012, "La estructura de la materia en los filósofos pluralistas presocráticos”, InterSedes: Revista de las Sedes Regionales, XIII (25): 143-168, disponible en $<$ http://www.redalyc.org/articulo.oa?id $=66623936008>$ (última consulta en diciembre de 2018).

CARREÑO, Miryam, 1991, "Almanaques y calendarios en la historia de la educación popular: un estudio sobre España", Revista de Educación, 296: 195-216.

CASTiBlANCO ROLDÁN, Andrés Fernando, 2010, "El Bristol: Rasgos e imágenes de lo popular", Cuadernos de Literatura del Caribe e Hispanoamérica, 12: 191-210. 
CHARRY JOYA, Carlos Andrés, 2002, “El trasfondo de la 'colombianización': el archipiélago de San Andrés visto por funcionarios del Estado colombiano (1888-1924)”, Revista Sociedad y Economía, 2: 73-94.

CORREA ARISTIZÁBAL, Sandra, 2013, Saber, Creer y Hacer: Conocimiento Etnoclimatológico en Providencia y Santa Catalina, Caribe Insular Colombiano. Medellín, Universidad de Antioquia, tesis doctoral.

DODGE, Robert K., 1985, "Four americanisms found in early almanacs", American Speech, 60 (3): 270-271.

DREW, Joshua, 2005, "Use of traditional ecological knowledge in marine conservation", Conservation Biology, 4 (19): 1286-1293.

DURA, Eliana de Freitas, 2005, Rebeldes Libertários: História e Identidade Nacional no Almanaque Brasileiro Garnier (1903-1914). Belo Horizonte, Editora UFMG.

EAMON, Michael J., 2012, “'Don't speak to me, but write on this': the childhood almanacs of Mary and Katherine Byles”, The New England Quaterly, 85 (2): 335-352.

FRANÇA JÚNIOR, Luis Celestino, 2007, "O juízo do ano: um estudo sobre o almanaque popular no Nordeste”, presentado en Intercom - V Congresso Nacional de História da Mídia, Sociedade Brasileira de Estudos Interdisciplinares da Comunicação, São Paulo, disponible en < https://plone.ufrgs.br/alcar/encontros-nacionais-1/encontros-nacionais/5o-encontro-2007-1/O\%20Juizo\%20do\%20Ano.\%20Um\%20estudo\%20sobre\%20o\%20almanaque\%20popular\%20no\%20Nordeste.pdf > (última consulta en diciembre de 2018).

GDASAPSC - GOBERNACIÓN DEL DEPARTAMENTO DEL ARCHIPIÉLAGO DE SAN ANDRÉS, PROVIDENCIA Y SANTA CATALINA, 2012, Plan Departamental de Gestión del Riesgo: Archipiélago de San Andrés, Providencia y Santa Catalina. S.1., PNUD/Gobernación del Departamento del Archipiélago de San Andrés, Providencia y Santa Catalina.

GEERTZ, Clifford, 2003, La Interpretación de las Culturas. Barcelona, Gedisa.

GIMÉNEZ, Gilberto, 1995, "Modernización, cultura e identidad social”, Espiral, 1 (2): 35-55.

GLACKEN, Clarence J., 1996, Huellas en la Playa de Rodas: Naturaleza y Cultura en el Pensamiento Occidental, desde la Antigüedad al Siglo XVIII. Barcelona, Ediciones del Serbal.

GOLINSKI, Jan, 2003, “Time, talk, and the weather in eighteenth-century Britain”, en Sarah Strauss y Ben Orlove (comps.), Weather, Climate, Culture. Oxford y Nueva York, Berg, 17-38.

GUBER, Rosana, 201 1, La Etnografía: Método, Campo y Reflexividad. Buenos Aires, Siglo Veintiuno Editores.

GUERRERO ARIAS, Patricio, 2002, Guía Etnográfica: Sistematización de Datos sobre la Diversidad y la Diferencia de las Culturas. Quito, Abya-Yala.

GUEVARA, Natalia, 2007, "San Andrés Isla, memorias de la colombianización y reparaciones", en Claudia Mosquera Rosero-Labbé y Luiz Claudio Barcelos (comps.), Memorias de la Esclavitud y Justicia Reparativa para Negros, Afrocolombianos y Raizales. Bogotá, Universidad Nacional de Colombia/Observatorio del Caribe Colombiano, 295-318.

HETHERINGTON, Norriss S., 1975, "Almanacs and the extent of knowledge of new astronomy in the seventeenth-century England", Proceedings of the American Philosophical Society, 119 (4): 275-279.

HOWELL, Signe, 2001, “iNaturaleza en la cultura o cultura en la naturaleza? Las ideas chewong sobre los 'humanos' y otras especies”, en Philippe Descola y Gísli Pálsson (comps.), Naturaleza y Sociedad: Perspectivas Antropológicas. Coyoacán, Siglo Veintiuno Editores, 149-168. 
JORGENSON, Chester E., 1935, "The new science in the almanacs of Ames and Francis", The New England Quaterly, 8 (4): 551-561.

KERR, Richard A., 1982, "Almanacs forecast questioned", Science, 215: 954.

KING, Darren, Apanui SKIPPER, y Wiremu Bill TAWHAI, 2008, "Māori environmental knowledge of local weather and climate change in Aotearoa, New Zealand", Climatic Change, 90 (4): 385-409.

LEJANO, Raúl, Joana TAVARES-REAGER, y Fikret BERKES, 2013, "Climate and narratives: environmental knowledge in everyday life”, Environmental Science and Policy, 31: 61-70.

LEMA VELÉZ, Luisa Fernanda, et al., 2017, "Climate change communication in Colombia”, Oxford Research Encyclopedia of Climate Science, DOI: 10.1093/acrefore/978019022 8620.013 .598$.

LÓPEZ-AUSTIN, Alfredo, 1995, "Equilibrio y desequilibrio del cuerpo humano: las concepciones de los antiguos nahuas", en J.M. López Piñero y J.L. Frequet Febrer (comps.), El Mestizaje Cultural y la Medicina Novohispánica del Siglo XVI. València, Universitat de València, 25-70.

LÓPEZ PIÑERO, José María, y José Luis FREQUET FEBRER, 1995, “El mestizaje cultural y la medicina novohispánica del siglo XVI y su influencia en Europa”, en J.M. López Piñero y J. L. Frequet Febrer (comps.), El Mestizaje Cultural y la Medicina Novohispánica del Siglo XVI. València, Universitat de València, 9-23.

MARIN, Andrei, y Fikret BERKES, 2013, "Local people's accounts of climate change: to what extent are they influenced by the media?", Wiley Interdisciplinary Reviews: Climate Change, 4 (1): 1-8, DOI: 10.1002/wcc.199.

MÁRQUEZ PÉREZ, Ana Isabel, 2013, “Culturas migratorias en el Caribe colombiano: el caso de los isleños raizales de las islas de Old Providence y Santa Catalina", Memorias, 10 (19): 204-229.

MELO, Rosilene Alves de, 201 1, "Almanaques de cordel: do fascínio da leitura para a feitura da escritura, outro campo de pesquisas", Revista do Instituto de Estudos Brasileiros, 52: 107 -122, DOI: 10.11606/issn.2316-901X.v0i52p107-136.

MEZA RAMIREZ, Carlos Andrés, 2006, “Territorios de frontera: embate y resistencia en la cuenca del río Cacarica”, Universitas Humanística, 62: 385-429.

MORA NAWRATH, Héctor Ivan, 2010, "El método etnográfico: origen y fundamentos de una aproximación multitécnica”, Forum: Qualitative Social Forum Research, 11 (2): art. 10 , DOI: $10.17169 / \mathrm{fqs}-11.2 .1283$.

ORLOVE, Ben, et al., 2010, "Indigenous climate knowledge in Southern Uganda: the multiple components of a dynamic regional system", Climatic Change, 100 (2): 243-265.

PÁlSSON, Gísli, 2001, "Relaciones humano-ambientales: orientalismo, paternalismo y comunalismo”, en Philippe Descola y Gísli Pálsson (comps.), Naturaleza y Sociedad: Perspectivas Antropológicas. Coyoacán, Siglo Veintiuno Editores, 81-100.

PINEDA CAMACHO, Roberto, 1987, "El método etnográfico, un enfoque cualitativo de investigación social”, Textos y Contexto, 11 : 97-108.

ROBINSON SAAVEDRA, Dilia, 2005, "Pueblo raizal en Colombia”, en Carlos Parra Dussán y Gloria Amparo Rodríguez, Comunidades Étnicas en Colombia: Cultura y Jurisprudencia. Bogotá, Universidad del Rosario, 217-237.

RONCOLI, Carla, et al., 2003, “Meteorological meanings: farmers' interpretations of seasonal rainfall forecasts in Burkina Faso", en Sarah Strauss y Ben Orlove (comps.), Weather, Climate, Culture. Oxford y Nueva York, Berg, 181-202. 
RUDIAK-GOULD, Peter, 2011 , "Climate change and anthropology: the importance of reception studies, Anthropology Today, 27 (2): 9-12.

RUDIAK-GOULD, Peter, 2013, “'We have seen it with our own eyes': why we disagree about climate change visibility”, Weather, Climate y Society, 5 (2): 120-132.

STRAUSS, Sarah, 2009, "Global models, local risks: responding to climate change in the Swiss Alps", en Susan Crate y Mark Nuttall (comps.), Anthropology and Climate Change: From Encounters to Actions. Walnut Creek, CA, Left Press Coast, 166-174.

TADDEI, Renzo, 2005, "A comunicação social do clima: esboço de uma sociologia do campo da comunicação meteorológica no Nordeste Brasileiro", presentado en Simposio Internacional de Climatología: Una Hidrometerología de los Impactos Ambientales en Regiones Semiáricas, Fortaleza, disponible en < http://iri.columbia.edu/ taddei/sociologia. pdf $>$ (última consulta en diciembre de 2018).

TADDEI, Renzo, 2008, "A comunicação social de informações sobre tempo e clima: o ponto de vista do usuário", presentado en XV Congresso Brasileiro de Meteorologia, São Paulo, disponible en < https://www.researchgate.net/publication/215549635> (última consulta en diciembre de 2018).

TADDEI, Renzo, 2009, “Os profetas da chuva do sertão como produção midiática”, presentado en la reunión de la Latin American Studies Association, Rio de Janeiro, disponible en < https://wwww.researchgate.net/publication/268351525> (última consulta en diciembre de 2018).

TADDEI, Renzo, 2015, "O lugar do saber local (sobre ambiente e desastres)", en Antenora Siqueira et al. (comps.), Riscos de Desastres Relacionados à Água: Aplicabilidade de Bases Conceituais das Ciências Humanas e Sociais para a Análise de Casos Concretos. São Carlos, Rima Editora, 31 1-325.

ULLOA, Astrid, 2001, “Transformaciones en las investigaciones antropológicas sobre naturaleza, ecología y medio ambiente”, Revista Colombiana de Antropología, 37: 188-232.

UlloA, Astrid (comp.), 2011, Perspectivas Culturales del Clima. Bogotá, Ilsa/Universidad Nacional de Colombia.

VAN KESSEL, Juan, y Porfirio ENRÍQUEZ SALAS, 2002, Señas y Señaleros de la Santa Tierra: Agronomía Andina. Quito/Iquique, Abya Ayala/Iecta, disponible en < http://iecta.cl/biblio teca/libros/pdf/senas.pdf > (última consulta en diciembre de 2018).

VELÁSQUEZ CALDERÓN, Carolina, y Adriana SANTOS-MARTÍNEZ, 2010, "Vulnerabilidad socio-económica de los agricultores frente a huracanes", Gestión y Ambiente, 13 (1): 7-20.

WALLERSTEIN, Immanuel, 1996, "La construcción histórica de las ciencias sociales desde el siglo XVIII hasta 1945”, en Immanuel Wallerstein (comp.), Abrir las Ciencias Sociales: Reporte de la Comisión Gulbenkian para la Reestructuración de las Ciencias Sociales. Madrid, Siglo Veintiuno Editores, 3-36.

WEIR, Tony, Liz DOVEY, y Dan ORCHERTON, 2017, "Social and cultural issues raised by climate change in Pacific Island countries: an overview", Regional Environmental Change, 17 (4): 1017-1028.

WILSON, Peter, 2004, Las Travesuras del Cangrejo: Un Estudio de Caso Caribe del Conflicto entre Reputación y Respetabilidad. San Andrés Isla, Universidad Nacional de Colombia. 